\section{THE ORIGIN OF A LIMESTONE ROCK}

I N November, I845, I laid before the Literary and I Philosophical Society of Manchester my memoir : On some Microscopic Objects found in the Mud of the Levant and other Deposits ; with Remarks on the Mode of Formation of Calcareous and Infusorial Siliceous Rocks," which memoir was published in vol. viii. of the second series of the Society's Transactions. In that memoir I sought to demonstrate two things-Ist, that not only was Chalk made up of microscopic organisms, chiefly Foraminifera, as had recently been demonstrated by Ehrenberg, but that the fact was equally true and explanatory of the origin of all limestones except a few freshwater Travertins; 2nd, that some other extensive deposits, of submarine origin, in which no Foraminifera could now be detected, were not in the state in which they were originally accumulated. I concluded that Foraminifera had doubtless been present in them also, but that their calcareous shells had been dissolved out of them, and that this disappearance had been effected through the agency of water containing carbonic acid, at an early stage of the formation of these deposits. As is well known, this latter theory has been reproduced as a new one by some of the naturalists of the Challenger expedition, who have applied it to the explanation of phenomena of a substantially similar nature to those which $I$ endeavoured to account for, in the same way, more than thirty years previously.

I am indebted for the slab of limestone forming the subject of this communication to my friends the Messrs. Patteson, the marble merchants of Oxford Street, Manchester. This slab appears to illustrate in an exquisite manner both the theories to which I have just referred. It is a specimen of the Bolland limestone, which, when sawn through, was found to contain a large concamerated Nautiloid shell more than twelve inches in diameter, which appears to me to have been a true Nautilus, though the section has not passed exactly through its centre so as to reveal any portion of its siphuncle. In the various parts of this slab we find the calcareous material exhibiting different conditions. Throughout the greater part of its substance we have evidence that it has originated in an accumulation of minute calcareous organisms - especially Foraminifera-but most of these are disintegrated and display vague outlines, a condition which I presume has resulted from the action of the carbonic acid already alluded to.

Scattered through the slab are numerous dark-coloured patches of a substance apparently identical with what the late Dr. Mantell designated Molluskite, and which he belicved to be the remains of the soft animal substance of marine organisms. In many of these patches the Foraminiferous shells are better preserved than is the case with the rest of the matrix inclosing the large fossil shell. It appears as if this Molluskite had partially protected the calcareous Foraminifera from the solvent action which had disintegrated most of those forming the rest of the deposit.

But the most interesting features of the specimen are seen within the chambers of the Nautiloid shell. The Foraminiferous ooze has entered freely through the large, open mouth of the terminal chamber in which the animal resided and filled the entire cavity of that chamber. There is no doubt whatever as to the original identity in the character of the ooze thus inclosed within the shell and that which constitutes its investing matrix, though they now appear very different. The latter portion was frecly permeated by water containing the solvent carbonic acid : hence the more or less complete disintegration of its Foraminiferous shells. But in the limestone inclosed

$x$ "On the Microscopic Conditions of a Slab from the Mountain Limestone of Bolland," by W. C. Williamson, F.R S., Professor of Natural Ifisstone of Bolland," College. Read before the Literary and Philosophical tory in Owens College. Read within the large terminal chamber of the Nautiloid shell almost every Foraminifer is preserved in the most exquisite perfection. This is especially the case in the deeper part of the chamber, most remote from the mouth, as also in the instances of one or two of the more internal closed chambers, into which the mud has obtained entrance through small accidental fractures in the outer shellwall. It appears obvious to me that the thick calcareous shell of the Nautilus has protected the inclosed shells of the Foraminifera from the action of the solvent acid. I repeat that there is no room whatever for doubting that both portions of the Foraminiferous ooze, whether contained within or surrounding the Nautiloid shell, were originally in identical states. Microscopic observation makes this sufficiently plain. The differences now observable between them have arisen from changes which have taken place subsequent to their primary accumulation, and which changes have been due to differences of position; the one portion has been protected by the thick calcareous Nautiloid shell which would rob the water percolating through it of all its solvent carbonic acid, and thus preserve the contained Protozoa from destruction, and which protection would continue so long as any portion of the Nautiloid shellwall remained undissolved. The other, being unprotected, would be exposed to the full action of the solvent, which would percolate readily amongst the loosely aggregated microscopic organisms, and speedily act upon their fragile shells.

But there is a yet further feature in this interesting specimen requiring notice. The closed chambers of the Nautiloid shell are all filled with clear, crystalline, calcareous spar. The acidulated water, acting upon the calcareous Foraminifera of the ooze has become converted into a more or less saturated solution of carbonate of lime. This has passed, by percolation, through the shell of the Nautilus into its hollow chambers. Finding there suitable cavities it has gradually filled them up with a crystalline formation of calcareous spar, and which of course exhibits no traces of the minute organisms from which the calcareous matter was primarily derived. A similar crystallisation has filled up the smaller interspaces between the Foraminiferous atoms both inclosed within, and external to, the Nautilus, rendering the limestone capable of receiving a high polish.

If these explanations are as correct as I believe them to be, we have here the entire history of the origin of a limestone rock-from the first accumulation of the Furaminiferous ooze, as seen in the interior of the first large chamber of the Nautilus, to the deposition, in an inorganic mineral form, of the crystallised carbonate of lime within the closed chambers of the Nautilus, all being illustrated within the area of a slab of limestone little more than a foot in diameter.

\section{THE LIOUEFACTION OF THE GASES}

$\mathrm{N}$ the recent article, in which the magnificent results recently obtained by $\mathrm{MM}$. Cailletet and Pictet were detailed, we contented ourselves, in the account of the methods employed, by pointing out the extreme simplicity of that used by $M$. Cailletet. The 'simplicity, however, by no means takes away from the beauty of the method, and we now propose to return to it with a view of showing how closely it resembles in many of its details that employed by Dr. Andrews in his classical work on the continuity of the various states of matter.

Dr. Andrews, it will be remembered, in his experiments on the liquefaction of carbonic acid, used a glass tube capillary in the upper part, and in the remainder, of a bore just so wide that a column of mercury would remain in it when the tube was held in a vertical position. The gas to be operated on was confined to the narrow upper part of the tube by mercury, and the tube was tightly packed to an end piece of brass armed with a flange. 